\title{
Changes in the cellulose fiber wall supramolecular structure during the initial stages of chemical treatments of wood evaluated by NMR and X-ray scattering
}

\author{
Elisabet Brännvall $(\mathbb{D} \cdot$ P. Tomas Larsson $\cdot$ Jasna S. Stevanic $\mathbb{C}$
}

Received: 7 May 2020/ Accepted: 19 February 2021 / Published online: 9 March 2021

(C) The Author(s) 2021

\begin{abstract}
The effect of initial stages of pulping of spruce, resembling prehydrolysis and alkaline cooking was studied using CP/MAS ${ }^{13} \mathrm{C}-\mathrm{NMR}, \mathrm{X}$-ray scattering, FSP and carbohydrate composition in order to study the impact of the pre-treatments on the fiber wall nanostructure. Removal of fiber wall components, hemicellulose and lignin, increased the fiber wall porosity and induced cellulose fibril aggregation. The effect of temperature and $\mathrm{pH}$ in the treatment on cellulose fibril aggregate size appears to be secondary. It is the removal of hemicellulose that has a profound effect on the supramolecular structure of the cellulose fiber wall. As the amount of hemicellulose dissolved from wood increases, the fibril aggregate size determined by NMR increases as well, ranging from 16 to $28 \mathrm{~nm}$. Specifically, a good correlation between the amount of glucomannan in the fiber wall and the fibril aggregate size is seen. The lower the amount of glucomannan, the larger the aggregate size. Glucomannan thus seems to prevent aggregation as it acts as a very efficient spacer between fibrils. Elemental fibril size determined by NMR, was quite similar for all samples, ranging from 3.6 to $4.1 \mathrm{~nm}$. By combining measurement methods, a more well-resolved picture
\end{abstract}

of the structural changes occurring during was obtained.

Keywords Fibril aggregation · Fiber wall porosity · Hemicellulose $\cdot$ Lignin $\cdot$ FSP

$\begin{array}{ll}\text { Abbreviations } \\ \text { Ara } & \text { Arabinose } \\ \text { Cr } & \text { Crystallinity } \\ \text { d/rw } & \text { Dried and rewetted } \\ \text { FSP } & \text { Fiber saturation point } \\ \text { GGM } & \text { Galactoglucomannan } \\ \text { Glc } & \text { Glucose } \\ \text { LFAD } & \text { Lateral cellulose fibril aggregate dimension } \\ \text { LFD } & \text { Lateral cellulose fibril dimensions } \\ \text { Man } & \text { Mannose } \\ \text { nd } & \text { Never-dried } \\ \text { o.d. } & \text { Oven dry } \\ \text { SDD } & \text { Sample to detector distance } \\ \text { SAXS } & \text { Small angle X-ray scattering } \\ \text { SSA } & \text { Specific surface area } \\ \text { WAXS } & \text { Wide angle X-ray scattering } \\ \text { XRD } & \text { X-ray diffraction } \\ \text { Xyl } & \text { Xylose }\end{array}$

E. Brännvall $(\bowtie) \cdot$ P. T. Larsson · J. S. Stevanic RISE Bioeconomy and Health, RISE INNVENTIA AB, Drottning Kristinas väg 61, Box 5604, 11486 Stockholm, Sweden

e-mail: elisabet.brannvall@ri.se 


\section{Introduction}

The biopolymers in plant cell walls interact with each other through hydrogen bonds, van der Waals interactions and electrostatic forces, forming a supramolecular structure of the fiber wall. In this work two terms are used to describe the building blocks of the supramolecular structure of cellulose I $\beta$; fibrils and fibril aggregates. In cellulose isolated from e.g. spruce by kraft pulping a cellulose fibril has a lateral dimension of about $4 \mathrm{~nm}$, fibrils can aggregate into bundles of fibrils with close-to co-linear main axes to form fibril aggregates. The lateral dimensions of fibril aggregates can range from bundles of a few fibrils up to widths of several tenths of nanometers. Within a fibril $\beta$-(1,4)-D-glucan polymers are tightly packed into fibrils with a cellulose I lattice at their core, and further arranged into fibril aggregates, surrounded by a matrix of hemicelluloses and lignin (e.g. Page 1976; Salmén and Olsson 1998; Fahlén and Salmén 2005). In addition to fibrils, the nanoscale supramolecular structure of the cell wall contains the empty spaces between the fibrils which form pores. The supramolecular structure and composition of the cell wall polymers can vary depending upon the biomass source, for example, the cellulose fibril width in spruce has been reported to be $4 \mathrm{~nm}$ (Hult et al. 2001), in cotton linters it is shown to be $7 \mathrm{~nm}$ while for tunicate cellulose it is $11 \mathrm{~nm}$ (Malm et al. 2010) and fibril aggregate sizes are 15,40 and $38 \mathrm{~nm}$ respectively.

Thermal and chemical processes affect the supramolecular structure of the fiber wall. Hydrothermal treatments, such as autohydrolysis, dilute acid pretreatment and steam explosion, result in increased aggregate size (Inagaki et al. 2010; Driemeier et al. 2011; Nishiyama et al. 2014; Kafle et al. 2015). Alkaline processes, such as kraft pulping, also lead to an increase of the fibril aggregate size (Hult et al. 2001; Fahlén and Salmén 2003, 2005). In both acidic and alkaline processes hemicelluloses are removed to different extent while lignin is redistributed by acidic hydrothermal treatments and dissolved in alkaline treatments. When the matrix material is dissolved, fibril surfaces are exposed, and aggregation of cellulose fibrils may occur. However, when matrix polymers remain on fibril surfaces, it can be assumed that they can act as spacers, preventing fibril aggregation (Hult et al. 2001). Fibril aggregation has also been explained as an entropy driven process (Langan et al. 2014; Pingali et al. 2014).

The supramolecular structure of the cell wall has a significant importance in many conversion processes of biomass. In the production of biofuel by enzymatic hydrolysis of polysaccharides, the accessibility of the fiber wall to enzymes is crucial (Adani et al. 2011; Aldaeus et al. 2015; Peciulyte et al. 2015). Accessibility also affects the reactivity of cellulose in derivatization processes for example manufacturing of cellulose acetate (Chunilall et al. 2010) or viscose fibers (Wollboldt et al. 2010). The fiber wall nanostructure affects product properties as well, such as the paper strength (Larsson and Salmén 2014), quality of nanocellulose (Pääkkö et al. 2007) or mechanical properties of bio-composites of cellulose (Nilsson et al. 2012). It is therefore of immense economical interest to understand how different conditions affect the supramolecular structure to be able to modify the process conditions in order to obtain pulps with highly accessible fiber walls and highly reactive cellulose.

The bulk of previous studies on supramolecular structure have analyzed the effect of process conditions after completed treatment, for example after hydrothermal treatment or after pulping. Duchesne and Daniel (2000) and Hult et al. (2001) studied ultrastructural changes occurring during kraft pulping, also in the initial stages of the process. However, to get a fundamental understanding of what initiates aggregations and affects fiber wall porosity, the present study investigates the changes in fiber wall nanostructure at the very initial stages of both acidic and alkaline treatments, resembling the conditions in the most common pulping processes, i.e. kraft and prehydrolysis kraft cooking. Apart from using the well-established method of NMR (e.g. Larsson et al. 1997; Hult et al. 2001) to study the supramolecular structure of the cellulose fiber wall, the samples were also analyzed by small- and wide-angle $\mathrm{x}$-ray scattering.

\section{Methods and materials}

Materials

Industrially produced never-dried spruce chips (Picea abies) were used in this study. The chips were stored at $-25{ }^{\circ} \mathrm{C}$. 
Chemicals

For wood chip treatment, stock solutions of $\mathrm{NaOH}$ and $\mathrm{H}_{2} \mathrm{SO}_{4}$ were made from ampoules (VWR International $\mathrm{AB})$ and diluted with de-ionized water. For chlorite delignification, $\mathrm{NaClO}_{2}, \mathrm{NaOH}$ pellets, and glacial acetic acid were delivered by Merck KGaA, Darmstadt, Germany. Dextran, from Leuconostoc mesenteroides, molecular mass approx. 1500-2800 kDa, CAS No. 9004-54-0; Sigma-Aldrich, Saint Louis, MO 63103, USA.

\section{Methods}

Treatment of wood chips

Before the chip treatments, the frozen chips were thawed at room temperature. The dry content was subsequently gravimetrically determined to be $52 \%$ by drying in oven at $105{ }^{\circ} \mathrm{C}$. Batches of $50.0 \mathrm{~g}$ chips (oven dry content) were prepared and placed in steel autoclaves with a volume of $3 \mathrm{~L}$. The air was removed from the autoclave by vacuum suction for $30 \mathrm{~min}$ after which the treatment liquor was sucked into the autoclaves to obtain a liquor-to-wood ratio of $6 \mathrm{~L} /$ $\mathrm{kg}$. The conditions during the treatments are presented in Table 1. Treatment at the lower temperature was performed by mounting the autoclaves in a glycol bath holding $110{ }^{\circ} \mathrm{C}$ and after a heating time of $10 \mathrm{~min}$, the treatment time was started. The alkaline extraction at the higher temperature was performed by starting the treatment at $100{ }^{\circ} \mathrm{C}$ and increasing the temperature with a rate of $3{ }^{\circ} \mathrm{C} / \mathrm{min}$. When reaching $170{ }^{\circ} \mathrm{C}$, the treatment was stopped by cooling the autoclave in a water bath. The autohydrolysis at the higher temperature was performed by placing the autoclaves in the glycol bath at $170{ }^{\circ} \mathrm{C}$ and starting the treatment time after heating for $10 \mathrm{~min}$. The $\mathrm{pH}$ in the hydrolysate on completion of autohydrolysis was 4.1 at $110{ }^{\circ} \mathrm{C}, 3.5$ at $170{ }^{\circ} \mathrm{C}$, and 13.5 after the alkaline treatments. Residual alkali in liquor after alkaline treatments was $0.62 \mathrm{M}$ at $110{ }^{\circ} \mathrm{C}$ and $0.59 \mathrm{M}$ at $170{ }^{\circ} \mathrm{C}$.

\section{Chlorite delignification}

The model to determine fibril and fibril aggregate size by NMR is developed for cellulose-rich samples. Thus, the samples after pre-treatment were chlorite delignified prior characterization by NMR and X-ray scattering and measurement of FSP. Batches of $20 \mathrm{~g}$ of treated wood chips were chlorite delignified using a sodium chlorite $\left(\mathrm{NaClO}_{2}\right)$ solution under acidic conditions (22 $\mathrm{g}$ of $\mathrm{NaClO}_{2}, 80 \%$, was mixed with $2 \mathrm{~mL}$ of glacial acetic acid, $100 \%$, and $1000 \mathrm{~mL}$ deionized water) at room temperature, mild stirring with magnetic stirrer for $12 \mathrm{~h}$. After that the samples were washed with deionized water during the vacuum filtration using a $7 \mathrm{~cm}$ Büchner funnel and a Teflon wire mesh. The samples were then soaked in $0.1 \mathrm{M}$ sodium hydroxide $(\mathrm{NaOH})$ solution $(4 \mathrm{~g}$ of $\mathrm{NaOH}$ pellets were mixed with $1000 \mathrm{~mL}$ deionized water) at room temperature, mild stirring with magnetic stirrer for $6 \mathrm{~h}$. After that the samples were washed with deionized water during vacuum filtration using a $7 \mathrm{~cm}$ Büchner funnel and a Teflon wire mesh. This two-step procedure was repeated several times (7 times for samples $\mathrm{NaOH} 170$ and $\mathrm{H}_{2} \mathrm{O} 170,10$ times for sample $\mathrm{NaOH} 110$ and 13 times for sample $\mathrm{H}_{2} \mathrm{O} 110$ ) until the pulps produced became bright in color. One half of these four pulps were analyzed as never-dried while the other half were analyzed as dried (oven dried at $105{ }^{\circ} \mathrm{C}$ for $19 \mathrm{~h}$ ) and rewetted (soaked in deionized water for $24 \mathrm{~h}$ and vacuum filtrated using a $7 \mathrm{~cm}$ Büchner funnel and a Teflon wire mesh).

Table 1 Conditions for the treatment of wood chips. The liquor-to-wood ratio was $6 \mathrm{~L} / \mathrm{kg}$ dry wood

\begin{tabular}{llllcr}
\hline & $\mathrm{NaOH}(\mathrm{M})$ & $\mathrm{H}_{2} \mathrm{SO}_{4}(\mathrm{M})$ & Temperature $\left({ }^{\circ} \mathrm{C}\right)$ & Retention time at temperature $(\mathrm{min})$ & Sample ID \\
\hline Alkaline extraction & 1.1 & - & 110 & 30 & $\mathrm{NaOH} 110$ \\
& 1.1 & - & 170 & $0^{*}$ & $\mathrm{NaOH} 170$ \\
Autohydrolysis & - & 0.001 & 110 & 240 & $\mathrm{H}_{2} \mathrm{O} 110$ \\
& - & - & 170 & 30 & $\mathrm{H}_{2} \mathrm{O} 170$ \\
\hline
\end{tabular}

*The autoclaves were removed after the heating time, which was from room temperature to $170{ }^{\circ} \mathrm{C}$ at a rate of $3{ }^{\circ} \mathrm{C} / \mathrm{min}$ 


\section{Analysis}

Carbohydrate composition

The chemical composition was analyzed in duplicate for each sample. Wood and treated wood chips were extracted with acetone in a Soxtec apparatus according to SCAN-CM 49:03. All samples were subsequently ground through a 40 mesh grid. The samples were hydrolyzed at $121{ }^{\circ} \mathrm{C}$ in an autoclave with $0.4 \mathrm{M}$ $\mathrm{H}_{2} \mathrm{SO}_{4}$, according to SCAN-CM 71:09. The solubilized monosaccharides were quantified using an ion chromatograph coupled to a pulsed amperometric detector (IC-PAD). Acid-insoluble residue was determined gravimetrically according to TAPPI T222 om11. The acid-soluble residue was measured by UV spectrophotometry at $205 \mathrm{~nm}$ according to TAPPI UM 250. MilliQ water was used as blank and for the dilution of hydrolysate. The content of acid-soluble reside was calculated using the absorptivity coefficient $110 \mathrm{~L} / \mathrm{g} \mathrm{cm}$. The repeatability of the method has been determined on 10 duplicates. At $95 \%$ confidence level for total carbohydrates analysis, the repeatability is $<2.0 \%$, which includes uncertainty in dry content determination, sample weight determination, hydrolysis, dilution and IC.

\section{NMR}

NMR spectra were recorded on four never-dried (nd) and four dried and rewetted (d/rw) samples packed uniformly in a zirconium oxide $\left(\mathrm{ZrO}_{2}\right)$ rotor with a $4 \mathrm{~mm}$ outer diameter. CP/MAS ${ }^{13} \mathrm{C}-\mathrm{NMR}$ spectra were recorded at $295 \pm 1 \mathrm{~K}$ on a Bruker Avance III AQS $400 \mathrm{SB}$ instrument operating at 9.4 T. NMR spectra were recorded on water swollen samples with a solids content of about $50 \%$ by weight. The MAS rate was $10 \mathrm{kHz}$. A $4 \mathrm{~mm}$ double air-bearing probe was used. Acquisition was performed with a CP pulse sequence, using a 2.95 microseconds proton $90^{\circ}$ pulse, 800 microseconds ramped (100-50\%) falling contact pulse and a $2.5 \mathrm{~s}$ delay between repetitions. A SPINAL64 pulse sequence was used for ${ }^{1} \mathrm{H}$ decoupling. Alpha-glycine $\left(\mathrm{NH}_{2} \mathrm{CH}_{2} \mathrm{COOH}\right)$ was used for the Hartmann-Hahn matching procedure, as well as an external standard for calibration of the chemical shift scale relative to tetramethylsilane $\left(\left(\mathrm{CH}_{3}\right)_{4} \mathrm{Si}\right)$. The data point of maximum intensity in the alpha-glycine carbonyl $(\mathrm{C}=\mathrm{O})$ signal was assigned a chemical shift of $176.03 \mathrm{ppm}$. Spectral fitting was performed using software, based on the LevenbergMarquardt algorithm, developed at RISE (Larsson et al. 1997). From NMR spectra the lateral cellulose fibril dimensions (LFD) and the lateral cellulose fibril aggregate dimension (LFAD) can be determined (Larsson et al. 1997; Wickholm et al. 1998). In fiber samples with high cellulose content $(>90 \%)$ the specific surface area (SSA) of the fiber in a water swollen state can be determined using the LFAD obtained from spectra fitting and the density of cellulose I $1500 \mathrm{~kg} / \mathrm{m}^{3}$ was used based on the dominating allomorph found in higher plants; cellulose I $\beta$ (Chunilall et al. 2010). The treatments are not expected to change the allomorph as a much higher temperature is needed for this to happen (Yamamoto and Horii 1993; Kuribayashi et al. 2016).

Fiber saturation point measurements and fiber wall pore size

Fiber saturation point (FSP) measurements were conducted in a manner similar that of Stone and Scallan (1967) but using only one high molecular mass dextran. Water-swollen samples with a known solids content were mixed with a dextran solution of known concentration (approximately 1\%, dextran mass/solution mass) in deionized water, approximately 1 mass unit of wet sample mass being mixed with 3 mass units of dextran solution. After mixing, the sample was stored in a sealed vessel at room temperature for 3 days to equilibrate. A liquid sample was subsequently taken and filtered through a Puradisc syringe filter (Whatman, Maidstone, UK) equipped with a $0.45 \mu \mathrm{m}$ polytetrafluoroethylene membrane in a polypropylene housing (VWR International $\mathrm{AB}$, Stockholm, Sweden). The concentration of dextran in the sample was determined using a calibration curve established for the optical rotation of polarized light measured using a Polartronic M100 Touch polarimeter (Schmidt + Haensch GmbH \& Co., Berlin, Germany) operating at $589 \mathrm{~nm}$, with a resolution of $0.001^{\circ}$ (angular degree) and a precision of $\pm 0.005^{\circ}$ at $589 \mathrm{~nm}$. The calibration curve was computed using three dextran concentrations: approximately $0.5,1.0$ and $1.5 \%$ (dextran mass/solution mass), covering the range of all measurements. Dynamic light scattering was used to determine the hydrodynamic diameter of the dextran molecules (Dextran 1500-2800, CAS No. 
9004-54-0) at high dilution in deionized water (Zetasizer ZEN3600; Malvern Instruments Ltd., Malvern, UK), using a $\mathrm{He}-\mathrm{Ne} 4.0 \mathrm{~mW}, 633 \mathrm{~nm}$ laser and a detector angle of $178^{\circ}$. The hydrodynamic diameter was found to be $97 \pm 2 \mathrm{~nm}$ with a polydispersity index of 0.2 , measured at a dextran concentration of $0.15 \mathrm{~g}$ dextran per L solution. Based on the determined size of the dextran, the results obtained for the FSP were interpreted as representing liquid contained in pores smaller than approximately $97 \mathrm{~nm}$ in diameter. The FSP value is expressed as the dimensionless ratio of the mass of pore water to the mass of dry solids $(\mathrm{g} / \mathrm{g})$.

Since both the FSP measurements and solid-state NMR measurements were performed on water swollen pulp these results can be combined, and this was utilized for calculating estimates of average fiber wall pore sizes. Average fiber wall pore sizes were computed by combining estimates of the specific surface area estimates from NMR spectra with results from FSP measurements. Advantages of this approach is that average pore sizes can be estimated without the need for sample drying and no pore geometry needs to be assumed (Larsson et al. 2013).

The average fiber wall pore size was calculated from the following relation:

$2 \mathrm{t}=2(\mathrm{FSP}) /\left(\sigma \cdot \rho_{L}\right)$.

where $2 t$ is the reported value for the average pore size, FSP is the fiber saturation point, $\sigma$ is the cellulose specific surface area from solid state $\mathrm{NMR}$, and $\rho_{\mathrm{L}}$ is the density of water. Although no particular pore geometry is assumed for the estimation of the average pore size, the reported value $2 t$ should be comparable to average pore diameters as reported by other measurement methods (Larsson et al. 2013).

X-ray measurements

X-ray measurements were performed on an Anton Paar SAXSpoint 2.0 system (Anton Paar, Graz, Austria) equipped with a Microsource X-ray source $(\mathrm{Cu} \mathrm{K} \alpha$ radiation, wavelength $0.15418 \mathrm{~nm})$ and a Dectris 2D CMOS Eiger R 1M detector with $75 \mu \mathrm{m}$ by $75 \mu \mathrm{m}$ pixel size.

All measurements were performed with a beam size of approximately $500 \mu \mathrm{m}$ diameter, at a sample stage temperature of $25{ }^{\circ} \mathrm{C}$ with a beam path pressure at 1-2 mBar. For WAXS the sample to detector distance
(SDD) was $109.1 \mathrm{~mm}$ and, for SAXS the SDD was $561.9 \mathrm{~mm}$.

All samples were mounted on a Multi-Paste Holder mounted on a Heated Sampler and a VarioStage (Anton Paar, Graz, Austria). The samples were kept between Kapton foils in hermetically sealed compartments and were not exposed to vacuum during measurement.

For each sample 5 frames each of 6 min duration were read from the detector, giving a total measurement time of 30 min per sample. For all samples the transmittance was determined and used for scaling of the scattering intensities. For wet samples, scattering data recorded on deionized water with same experimental setup was used for background subtraction.

The software used for instrument control was SAXSdrive version 2.01.224 (Anton Paar, Graz, Austria), and post-acquisition data processing was performed using the software SAXSanalysis version 3.00.042 (Anton Paar, Graz, Austria).

The distance between the center of adjacent fibrils (symbol $\mathrm{d}_{\text {center }}$ ) was estimated from the maximum in the Kratky plot $\left(d=\frac{2 \pi}{q_{\max }}\right)$ as suggested by Virtanen et al. (2015). A Kratky plot is a presentation of SAXS data where the observed scattering intensity I(q) multiplied by the squared value of the scattering vector $\mathrm{q}$, is charted against the scattering vector; a plot of $I(q) q^{2}$ vs. q. Kratky plots can be used as a tool to obtain information on the persistence length of polymers in solution (Cleland 1977), but it has also found use as a tool for characterizing the fiber wall structure in pulps. Virtanen et al. (2015), utilized Kratky plots for qualitatively monitoring changes in the average distances between fibrils in spruce pulps. The average distances determined by this method are here denoted $\mathrm{d}_{\text {center }}$. As discussed by the authors (Virtanen et al. 2015) the determined $d_{\text {center }}$ distances may not represent the exact distances between fibril center points, but can be used to establish correlations with exact distances, suitable for comparisons between similar samples. The interpretation of the $d_{\text {center }}$ values as fibril center-to-center distances can be complicated in cases of compact cellulose fibril aggregate interiors, tightly packed fibrils may limit electron density contrast to the point where individual fibrils could not be distinguished. Further, changes of large-scale structures (outside the used SAXS detection range) can 'tail' scattering intensity into the detected region, 
possibly contributing to a shift in the position of the Kratky plot maximum. For these reasons the determined $d_{\text {center }}$ values were used mainly for qualitative comparisons. A fitting of the Kratky curve was made (see Fig. 6) to identify the position of the maximum, used to calculate $d_{\text {center }}$. The average crystallite size,

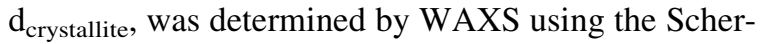
rer equation applied to the (200) signal.

\section{Results}

Never-dried spruce chips were treated at $110{ }^{\circ} \mathrm{C}$ and $170{ }^{\circ} \mathrm{C}$, at acidic and alkaline $\mathrm{pH}$, resembling the conditions in the most common pulping processes, i.e. kraft and prehydrolysis kraft cooking. The aim was to study the initial effects of temperature and $\mathrm{pH}$ on the supramolecular structure of the fiber wall as well as the effect of drying. The treated wood samples were chlorite delignified prior to analysis. In Table 2, the chemical composition after treatment and after chlorite delignification is shown.

The supramolecular structure of the chlorite delignified samples are shown in Table 3, both before and after drying in oven at $105{ }^{\circ} \mathrm{C}$. Never-dried wood chips were used to control the effect of the treatments and avoid the potential effect of drying on the supramolecular structure of the fiber wall. The fiber saturation point (FSP) was slightly reduced by a higher treatment temperature, both at alkaline and acidic conditions. At a given temperature, no significant difference was seen in FSP between alkaline and acid treatments. Drying reduced the FSP considerably. A higher $\mathrm{pH}$ in the treatment increased the pore size, whereas drying resulted in a decreased pore size.

Both higher temperature and $\mathrm{pH}$ during treatment decreased the specific surface area (SSA). The crystallinity was not affected by neither $\mathrm{pH}$ nor temperature. There was no significant effect on fibril thickness, the lateral fibril width (LFD), by treatment conditions or drying, the average was $3.8 \mathrm{~nm}$. However, the fibril aggregate size, lateral fiber aggregate dimension (LFAD), was increased by both higher temperature and $\mathrm{pH}$. Upon drying, LFAD remained on same level. The distance between adjacent fibril centers as estimated from the maximum of a SAXS Kratky plot, $\mathrm{d}_{\text {center, }}$, decreased with drying.

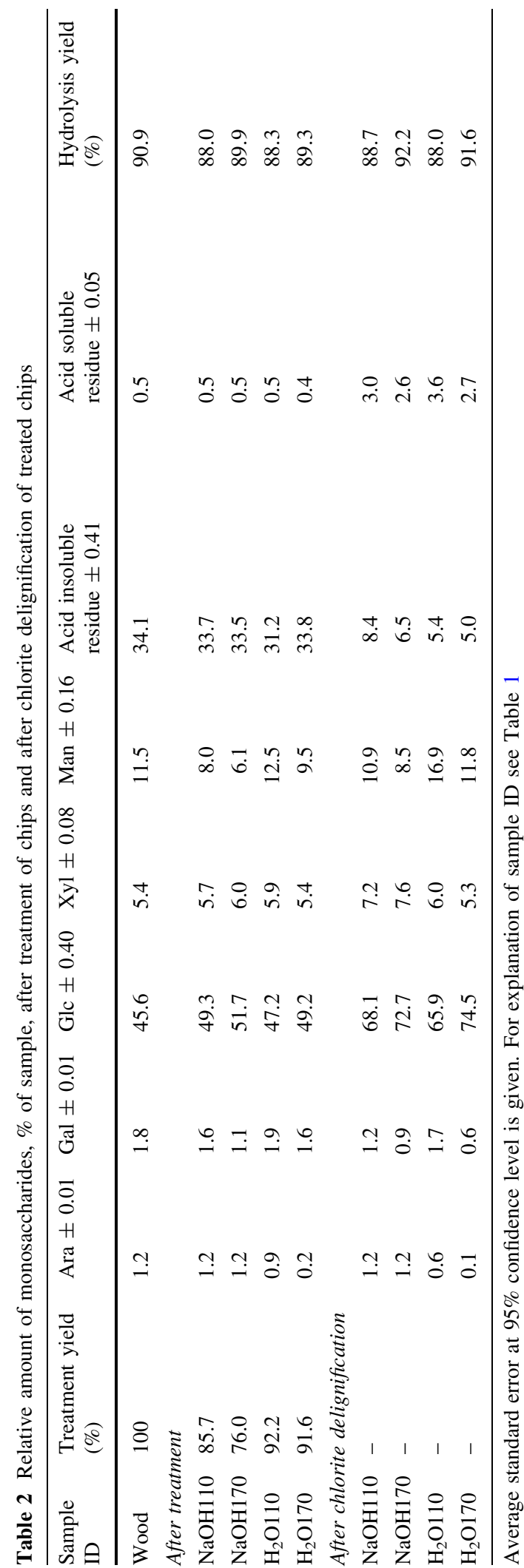


Table 3 Supramolecular properties of chlorite delignified fibers from NMR except $d_{\text {center }}$, the distance between adjacent fibril centers which is estimated from the maximum of a SAXS Kratky plot and $\mathrm{d}_{\text {crystallite, }}$ which is the crystallite size from WAXS

\begin{tabular}{lrrrrrrrr}
\hline & FSP $(\mathrm{g} / \mathrm{g})$ & Pore size $(\mathrm{nm})$ & $\mathrm{SSA}\left(\mathrm{m}^{2} / \mathrm{g}\right)$ & $\mathrm{Cr}(\%)$ & LFD $(\mathrm{nm})$ & LFAD $(\mathrm{nm})$ & $\mathrm{d}_{\text {crystallite }}(\mathrm{nm})$ & $\mathrm{d}_{\text {center }}(\mathrm{nm})$ \\
\hline Never-dried & & & & & & & & \\
$\mathrm{NaOH} 110$ & $3.54 \pm 0.14$ & $56.3 \pm 5.3$ & $126 \pm 11$ & $48 \pm 3$ & $3.7 \pm 0.2$ & $21.2 \pm 1.8$ & 2.6 & $9.9 \pm 1.0$ \\
$\mathrm{NaOH} 170$ & $3.20 \pm 0.12$ & $66.6 \pm 5.2$ & $96 \pm 7$ & $49 \pm 1$ & $3.8 \pm 0.1$ & $27.8 \pm 1.9$ & 3.2 & $10.6 \pm 1.1$ \\
$\mathrm{H}_{2} \mathrm{O} 110$ & $3.50 \pm 0.03$ & $42.7 \pm 4.0$ & $164 \pm 15$ & $48 \pm 4$ & $3.7 \pm 0.2$ & $16.3 \pm 1.5$ & 2.5 & $9.0 \pm 0.9$ \\
$\mathrm{H}_{2} \mathrm{O} 170$ & $2.93 \pm 0.15$ & $46.2 \pm 4.0$ & $127 \pm 8$ & $52 \pm 3$ & $4.1 \pm 0.2$ & $21.0 \pm 1.3$ & 3.2 & $10.0 \pm 1.1$ \\
Dried and rewetted & & & & & & & \\
$\mathrm{NaOH} 110$ & $1.52 \pm 0.04$ & $23.0 \pm 1.3$ & $132 \pm 7$ & $47 \pm 1$ & $3.6 \pm 0.1$ & $20.2 \pm 1.0$ & 2.5 & $8.2 \pm 0.7$ \\
$\mathrm{NaOH170}$ & $1.39 \pm 0.06$ & $27.4 \pm 2.2$ & $102 \pm 7$ & $50 \pm 1$ & $3.9 \pm 0.1$ & $26.2 \pm 1.8$ & 3.4 & $8.3 \pm 0.8$ \\
$\mathrm{H}_{2} \mathrm{O} 110$ & $1.48 \pm 0.10$ & $18.1 \pm 2.0$ & $164 \pm 14$ & $44 \pm 1$ & $3.4 \pm 0.1$ & $16.3 \pm 1.4$ & 2.7 & $8.1 \pm 0.7$ \\
$\mathrm{H}_{2} \mathrm{O} 170$ & $0.71 \pm 0.15$ & $12.7 \pm 2.9$ & $111 \pm 10$ & $52 \pm 1$ & $4.1 \pm 0.1$ & $24.0 \pm 2.2$ & 3.4 & $8.0 \pm 0.5$ \\
\hline
\end{tabular}

\section{Discussion}

In Fig. 1 (top), the yield of the different compounds after treatment is shown. The amount of xylan, glucomannan, cellulose and lignin in the samples are calculated from the monosaccharides according to Janson (1974) using a mannose to glucose ratio of 4.2 in galactoglucomannan (GGM). The relative chemical composition in the treated samples is shown in Fig. 1 (bottom). The alkaline treatment dissolved a large part of the glucomannan. This is mainly due to the peeling reaction (e.gWigell et al. 2007; Paananen et al. 2013). The xylan content was decreased as well, primarily dissolved in polymeric form (e.g. Axelsson et al. 1962; Jansson and Brännvall 2011). In the acidic treatment, the content of arabinose, mannose and galactose was reduced, probably dissolved as mono- or oligosaccharides (e.g. Puls et al. 1985; Garrote et al. 1999; Chen et al. 2010; Borrega et al. 2011).

The increase in average pore size, correlates well with the amount of hemicellulose remaining, Fig. 2a, especially with glucomannan content in fibers, Fig. 2b. This is in accordance with previous studies showing that as wood matrix material is removed, new pores are generated and the size of existing pores increase in the fiber wall (Stone and Scallan 1967). Pores in pulp fibers have been reported to be in the range from 20 up to $50 \mathrm{~nm}$, increasing with degree of delignification (Andreasson et al. 2003).

LFAD increased with $\mathrm{pH}$ and temperature, showing a correlation both between total hemicellulose content, Fig. 2c, and glucomannan content, Fig. 2d. An increase in pore size with increased removal of glucomannan is thus accompanied by a decrease in specific surface area (increase in LFAD).

This is in accordance with earlier studies which have demonstrated that removal of hemicelluloses by hot water extraction results in a denser packing of fibrils and increased LFAD (Hult et al. 2001; Penttilä et al. 2013) and that increased glucomannan content results in smaller fibril aggregate size in pulp fibers (Duchesne et al. 2001; Virtanen et al. 2015). This might be due to the closer association between glucomannan and cellulose compared to xylan and cellulose (Åkerholm and Salmén 2001; Salmén and Olsson 1998). Jungnikl et al. (2008) saw that chlorite delignification had only small effect on the nanostructure of the call wall whereas removal of glucomannan by alkali changed it significantly (Jungnikl et al. 2008).

Interestingly, effect of temperature and $\mathrm{pH}$ seems to be secondary. The total hemicellulose content after treatment with alkali at $110{ }^{\circ} \mathrm{C}$ for $30 \mathrm{~min}$ $\left(\mathrm{NaOH} 110^{\circ} \mathrm{C}\right)$ and at acidic $\mathrm{pH}$ at $170{ }^{\circ} \mathrm{C}$ for $30 \mathrm{~min}$ $\left(\mathrm{H}_{2} \mathrm{O} 170^{\circ} \mathrm{C}\right)$ was similar, and the size of the cellulose fibril aggregates was $21 \mathrm{~nm}$ in both cases.

In literature, the reported aggregate sizes range from 15 to $28 \mathrm{~nm}$ (Penttilä et al. 2013; Leppänen, et al. 2009). The aggregate sizes of the treated materials in the present study are within this range, reaching as high as $28 \mathrm{~nm}$. It has been shown previously that already during the heating phase of either alkaline pulping (Hult et al. 2001) or steam pre-treatment (Pingali et al. 2014) an increase in aggregate size is 
Fig. 1 Top panel: Yield of different components, $\%$ on oven-dry (o.d.) wood after alkaline $(\mathrm{NaOH})$ and acid $\left(\mathrm{H}_{2} \mathrm{O}\right)$ treatment at 110 and $170{ }^{\circ} \mathrm{C}$. Bottom panel: The relative sample compositions of GGM, xylan, cellulose and lignin after chlorite delignification

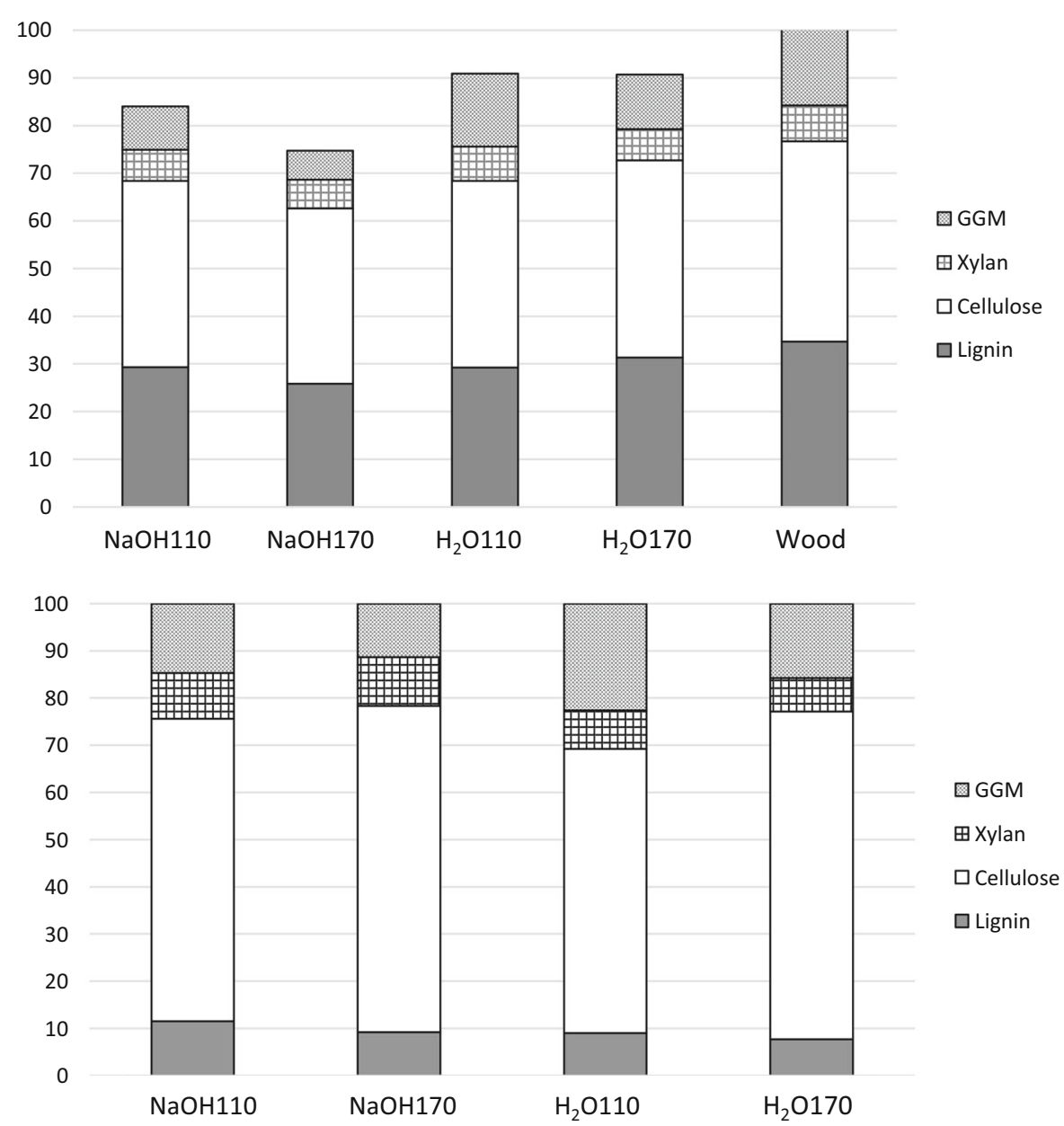

obtained. Matrix material acts as spacers between cellulose fibrils and when removed the cellulose chains on the surface of adjacent fibrils adjust to each other and form fibril aggregates, as schematically depicted in Fig. 3. The present study confirms that aggregation of fibrils occurs quite early in the process. Treatment of wood during short time, whether alkaline or acid and whether at relatively low temperature $\left(110^{\circ} \mathrm{C}\right)$ or high temperature $\left(170^{\circ} \mathrm{C}\right)$, leads to changes in the conformation of polysaccharide polymer chains to form structures of higher order.

Drying caused the largest decrease in pore size and pore volume (measured as FSP) for the $\mathrm{H}_{2} \mathrm{O} 170$ sample, the reduction was $72 \%$ and $76 \%$ respectively. For the other samples, the reduction was $58-60 \%$ in pore size and $50-58 \%$ in FSP. The SAXS measurements confirm the effect of drying on pores in the fiber wall, Fig. 4. The largest difference between nd and $\mathrm{d} / \mathrm{rw}$ samples was seen for $\mathrm{H}_{2} \mathrm{O} 170$. Interestingly, there was a difference between nd and $\mathrm{d} / \mathrm{rw}$ for $\mathrm{H}_{2} \mathrm{O} 170$ down to a q-value of about $21 / \mathrm{nm}$ (d-values about $3 \mathrm{~nm}$ ), while no effect of drying was seen for other samples below about $10 \mathrm{~nm}$.

The interpretation of the SAXS data is complicated by several factors. The structural nature of the fiber wall interior is composed of high aspect ratio cellulose fibrils that can form aggregates of different lateral dimensions, mixed with hemicellulose (and smaller amounts of lignin) which may change its spatial distribution within the fiber wall as a result of the nature of the pre-treatment. Partial removal of hemicellulose and lignin create pores with a size distribution that can cover the dimensional range probed in the SAXS measurements. The strategy for interpreting the SAXS data used here is to try establishing interpretations consistent with other measurement results 
Fig. 2 Pore size as a function of a total hemicellulose content and b glucomannan content. Lateral fibril aggregate dimensions (LFAD) as a function of $\mathbf{c}$ total hemicellulose content and d LFAD as a function of glucomannan content. Filled symbols represent neverdried samples, unfilled symbols represent dried and re-wetted samples. The samples were chlorite delignified after treatment in alkaline $(\mathrm{NaOH})$ or acidic $\left(\mathrm{H}_{2} \mathrm{O}\right) \mathrm{pH}$. The treatment time at temperature varied from 0 min for $\mathrm{NaOH} 170^{\circ} \mathrm{C}$ to $240 \mathrm{~min}$ for $\mathrm{H}_{2} \mathrm{O} 110^{\circ} \mathrm{C}$, see Table 1

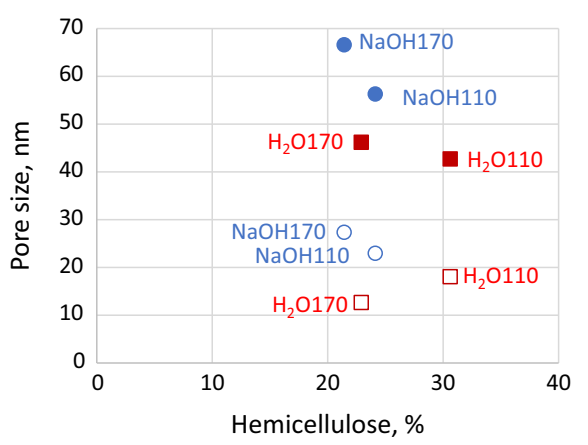

(a)

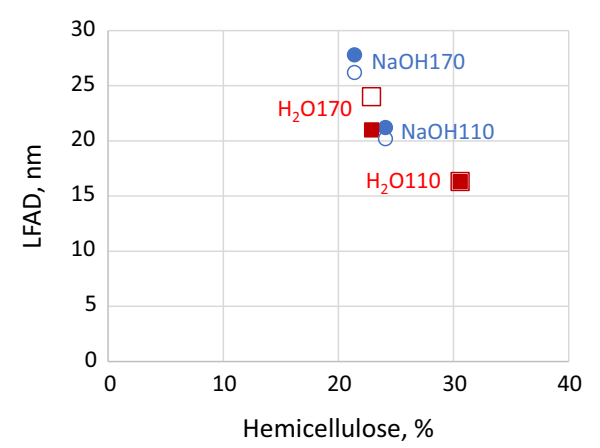

(c)

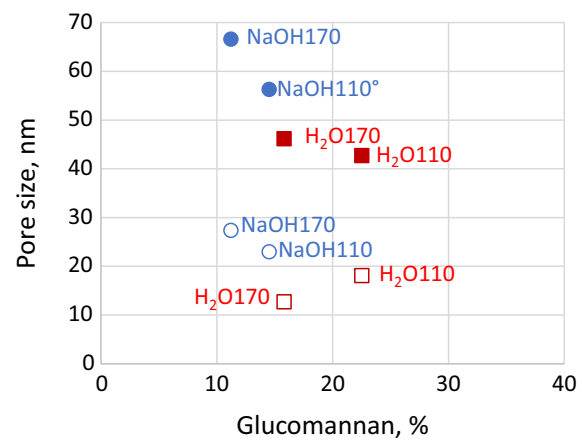

(b)

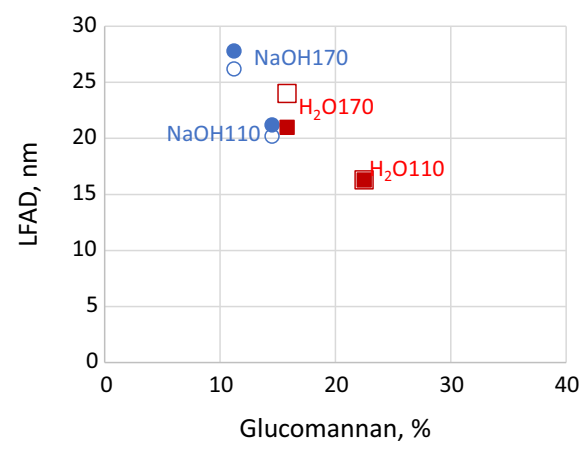

(d)



Fig. 3 An illustration of a model for a cross-section of a 6-by-6 fibril aggregate, with lignin (brown) and hemicellulose (green). The blue squares represent the cross-sections of individual cellulose fibrils. During processing, the lignin and hemicellulose content is depleted, allowing for intimate contacts between

(FSP, CP/MAS ${ }^{13} \mathrm{C}-\mathrm{NMR}$ ) and by doing so to obtain additional information on the fiber wall nanostructure.

Due to the differences in principles of operations between CP/MAS ${ }^{13} \mathrm{C}-\mathrm{NMR}$ and SAXS, it was not expected that agreements in absolute values would be

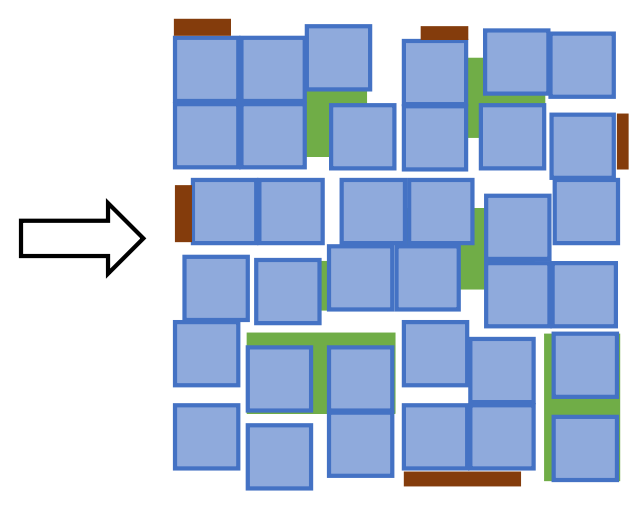

fibrils, leading to the formation of difficult-to-break-up aggregates of fibrils. The pattern of intimate contact between fibrils may vary in length direction (perpendicular to the depicted plane) yielding an overall cohesion for the fibril aggregate

found when measuring the same samples by the two techniques.

When comparing the SAXS data in Fig. 4 and the data in Table 3 some interesting features were observed. When never-dried and dried-and-rewetted samples are compared pairwise, the NMR data in 

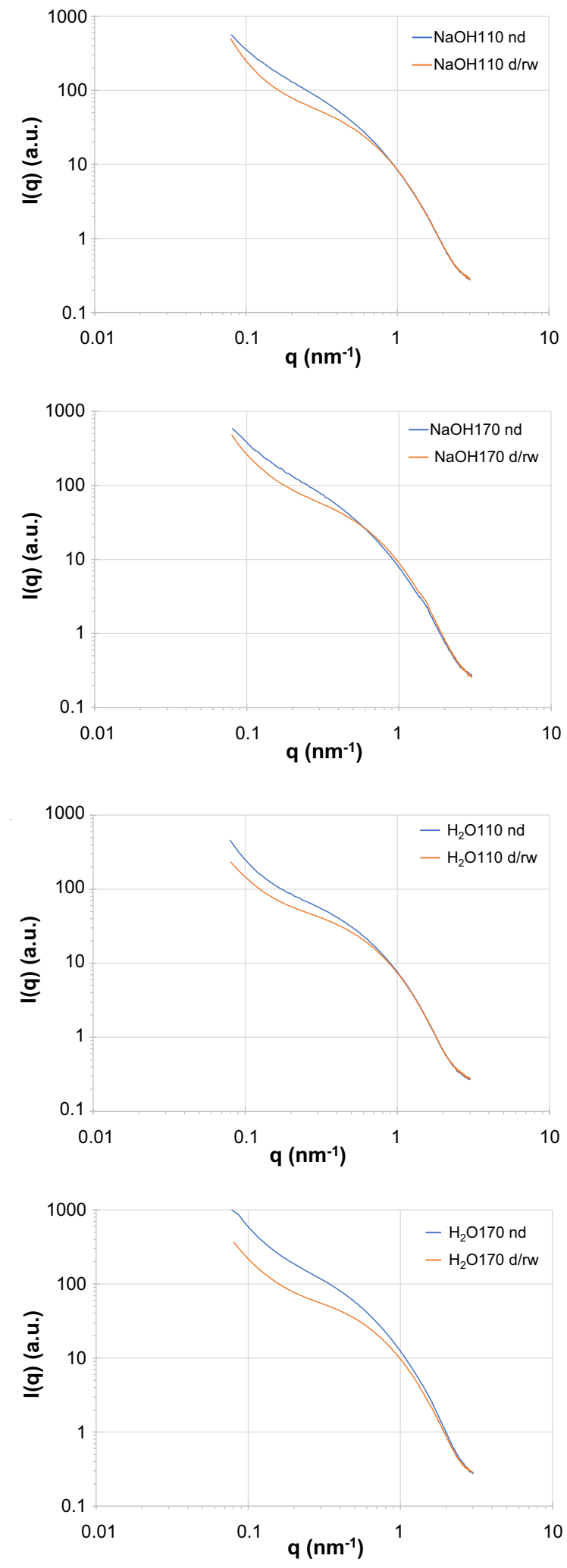

4Fig. 4 The SAXS profiles recorded on the NaOH110, $\mathrm{NaOH} 170, \mathrm{H}_{2} \mathrm{O} 110$ and $\mathrm{H}_{2} \mathrm{O} 170$ sample. The intensity scale (y-axis) is arbitrary units and the q-range is expressed in reciprocal nanometers $(1 / \mathrm{nm})$ Each panel contains data recorded on pairs of samples, never-dried and after drying and rewetting. The SAXS data has been transmittance scaled and background subtracted. The small signal feature present in the data for the $\mathrm{NaOH} 170$ sample at about $1.51 / \mathrm{nm}$ corresponds to the position of the detector gap in the Eiger R $1 \mathrm{M}$ detector and was a measurement artefact, confirmed by measurements using different SDD

Table 3 indicates that there were no statistically significant changes in LFAD because of drying and subsequent rewetting. The major changes were found in the FSP values, which reduced from 3.0 to $3.5 \mathrm{~g} / \mathrm{g}$ in never-dried samples to $0.7-1.5 \mathrm{~g} / \mathrm{g}$ after drying and rewetting. Also the average pore sizes, calculated from FSP and NMR data, decreased after drying, from 43 to $67 \mathrm{~nm}$ in never-dried samples to $13-27 \mathrm{~nm}$. For three of the samples, $\mathrm{NaOH} 110, \mathrm{NaOH} 170$ and $\mathrm{H}_{2} \mathrm{O} 110$, the average pore sizes decreased to roughly half their initial values after drying and rewetting. In the case of sample $\mathrm{H}_{2} \mathrm{O} 170$ the average pore size decreased to about a quarter of its initial value after drying and subsequent rewetting.

The NMR data thus showed that drying and subsequent rewetting did not change the size of fibril aggregates. Based on these observations it was concluded that the main structural factors influencing the recorded SAXS data, in these cases, relates to the fiber wall pore structure. In the SAXS data for all four samples a significant decrease in signal intensity was observed in the low q-range, correlating with the decrease in FSP values. For the $\mathrm{H}_{2} \mathrm{O} 170$ the difference in appearance of the SAXS profiles recorded before and after drying were the most pronounced, and particularly so at higher q-values. Consistent differences in SAXS profiles recorded on never-dried and dried-and-rewetted samples at q-values of about 1 $1 / \mathrm{nm}$ and larger was only found in the SAXS data from the $\mathrm{H}_{2} \mathrm{O} 170$ sample. This size range, about $6 \mathrm{~nm}$ and smaller, carries information about the internal structure of cellulose fibril aggregates. The acidic conditions in combination with a higher temperature could also explain the observed differences in the $\mathrm{H}_{2} \mathrm{O} 170$ SAXS data by a more efficient removal of hemicellulose from within the cellulose fibril aggregate. This way, the high acidity and high temperature wood chip pre-treatment efficiently removes hemicelluloses also 
from the more confined environments, allowing for a more profound pore collapse/aggregation when subsequently dried. This is in agreement with the observed differences in the FSP values.

Comparing the chemical composition of the samples, the $\mathrm{H}_{2} \mathrm{O} 170$ and $\mathrm{NaOH} 170$ showed the largest relative cellulose content, $81 \%$ and $80 \%$ respectively. The different chemical nature of the pre-treatments, acidic versus alkaline, may explain the difference observed in SAXS results. The more efficient breakdown of hemicellulose by the acidic pre-treatment alleviate the removal of hemicellulose from more confined environments, i.e. in the $\mathrm{H}_{2} \mathrm{O} 170$ sample. Spatial redistribution of hemicelluloses, due to higher solubility in alkali, does not occur for the more confined environments.

Using the method of Virtanen et al. (2015) for calculating an average distance between adjacent fibrils (the $d_{\text {center-value reported in Table } 3 \text { ) from a }}$ Kratky plot of the SAXS data, gave a reasonable correlation with FSP values between the groups of samples. The $\mathrm{d}_{\text {center-values were larger in the group of }}$ never-dried samples $(9-11 \mathrm{~nm})$ compared with the group of dried-and-rewetted samples $(8 \mathrm{~nm})$. However, there were no statistically significant differences found among the $d_{\text {center-values of the samples within }}$

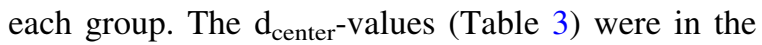
range of these reported by Virtanen et al. (2015) estimated on a commercial spruce-pine dissolving sulphite pulp that was mechanically and enzymatically pre-treated. Also, even though the $d_{\text {center-values did }}$ not represent the exact distances between adjacent fibrils, they could be used as a correlation to the true average distance and therefore suitable for comparisons among similar samples (Virtanen et al. 2015).

For the samples that were used in this study, an average distance between adjacent fibrils of 8-11 nm seems large. With an average lateral fibril dimension of about $4 \mathrm{~nm}$, this would imply a separation of 4-6 nm between fibrils within a fibril aggregate, contradicting aggregation. However, if the fibrils within a cellulose fibril aggregate are partially aggregated, i.e. there may exist some small-scale pore system also within the aggregate, combined with regions of very intimate contact between neighboring co-axial fibrils, the observed distances may not contradict the occurrence of aggregation. As indicated in Fig. 3, partial aggregation of fibrils forming a fibril aggregate may introduce some ambiguity about lateral

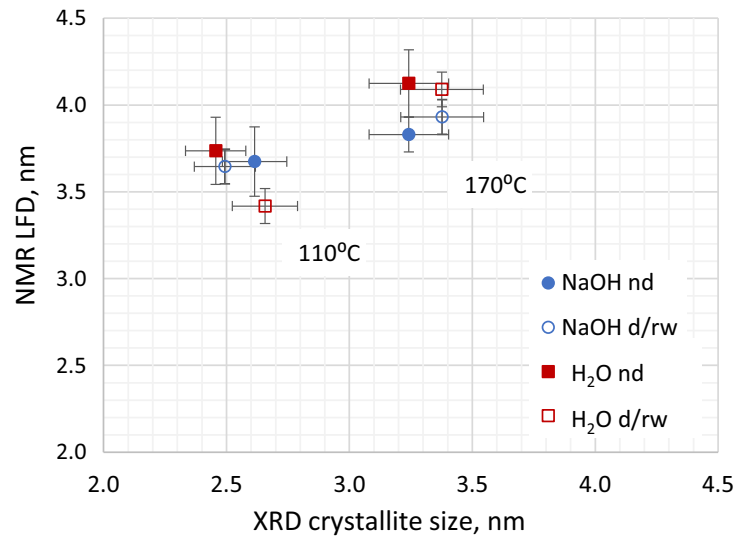

Fig. 5 The correlation between average lateral fibril dimensions (LFD), determined by CP/MAS ${ }^{13} \mathrm{C}$-NMR and the average crystallite sizes as determined by XRD using the Scherrer equation on the (200) signal. The error bars for LFD was taken from the NMR spectra fitting results, and for the crystallite sizes calculated error from 3 to 5 determinations was used

particle dimensions for scattering measurements. Intimate contact between neighboring co-axial fibrils may decrease electron density contrast between adjacent fibrils to the point where the width of two fibrils effectively is observed as a single particle. Due to the differences in operating principle between X-ray scattering and CP/MAS ${ }^{13} \mathrm{C}-\mathrm{NMR}$ spectroscopy, it is not certain that the two methods operationally define measures such as particle sizes and interparticle distances in the same manner. Focus is put on trends, where both methods give results that supports that drying and subsequent rewetting results in a more extensive consolidation/aggregation of cellulose fibrils.

The LFD determined by CP/MAS ${ }^{13} \mathrm{C}-\mathrm{NMR}$ were compared with the so-called crystallite dimensions determined from XRD diffractograms recorded on the samples. The results are shown as a correlation graph in Fig. 5. It was found that the data grouped with respect to maximum treatment temperature. The scatter within each temperature group prevented any detailed conclusions to be drawn, a statistically significant difference was found between the groups, showing that both NMR and X-ray indicated that the samples that had been exposed to higher temperatures showed the larger dimensions.

There is a correlation between LFD determined by NMR and crystallite size determined by XRD, Fig. 5 . As expected, the absolute numbers do not agree, but 
the observed trends are similar. Interestingly, the major impact on LFD/crystallite size was due to the treatment temperature, where a higher temperature resulted in an increased internal fibril order. Increased internal fibril order as the result of hydrothermal treatments has been observed previously (Hult et al. 2001).

Within this tentative interpretation of combined NMR, FSP and SAXS data it became possible to address a size range of the fiber wall difficult to reach by other means, the internal structure of cellulose fibril aggregates. The close-to co-axial alignment of the $4 \mathrm{~nm}$ wide cellulose fibrils in the fiber wall makes packing and aggregation efficient building fairly, but not completely, compact structures. Accessibility to the interior of $10-40 \mathrm{~nm}$ wide fibril aggregates becomes an important controlling factor for e.g. chemical reactivity and cellulose-water interactions since most of the surface area is exposed by the $4 \mathrm{~nm}$ wide fibrils. Increasing accessibility to the fibril aggregates interior makes more surface area exposed and available.

\section{Conclusions}

Spruce chips subjected to different pre-treatments were studied using X-ray scattering, CP/MAS ${ }^{13} \mathrm{C}$ NMR spectroscopy, FSP and carbohydrate composition in order to a study the impact of the pre-treatments on the fiber wall nanostructure.

All samples were subjected to a mild chlorite delignification prior to structural analysis.

Removal of fiber wall components, hemicellulose and lignin, increased the fiber wall porosity and induced cellulose fibril aggregation.

A pronounced correlation between GGM removal and cellulose fibril aggregation was found.

The NMR results showed that no major changes were observed in the LFAD as the result of drying and re-wetting. However, drying and re-wetting had a significant impact on the SAXS results, covering the size range smaller than that characteristic for fibril aggregate widths. Based on this an interpretation was made that the SAXS measurement gave information about changes in the interior structure of cellulose fibril aggregates, not necessarily associated with significant changes to the LFAD. A tentative explanation for these observations was that the internal aggregate structure is composed of intimately aggregated fibrils (partial aggregates) intermixed with small scale cavities between partial aggregates.

In summary, the effect of temperature and $\mathrm{pH}$ in the treatment on cellulose fibril aggregate size appears to be secondary. It is the removal of hemicellulose that has a profound effect on the supramolecular structure of the cellulose fiber wall. As the amount of hemicellulose dissolved from wood increases, the fibril aggregate size increases as well. Specifically, a good correlation between the amount of glucomannan in the fiber wall and the fibril aggregate size is seen. The lower the amount of glucomannan, the larger the aggregate size. Glucomannan thus seems to prevent aggregation as it acts as a very efficient spacer between fibrils.

By combining measurement methods, a more wellresolved picture of the structural changes occurring during wood chip pre-treatments was obtained.

Acknowledgments The authors gratefully acknowledge the financial support received from Önnesjöstiftelsen. This project has been co-financed with funds for strategic competence development to RISE from the Swedish state.

Funding Open access funding provided by RISE Research Institutes of Sweden.. Önnesjöstiftelsen and funds for strategic competence development to RISE from the Swedish state.

Availability of data and material Not applicable.

\section{Declarations}

Conflict of interest The authors declare no competing or conflicts of interest.

Open Access This article is licensed under a Creative Commons Attribution 4.0 International License, which permits use, sharing, adaptation, distribution and reproduction in any medium or format, as long as you give appropriate credit to the original author(s) and the source, provide a link to the Creative 
Commons licence, and indicate if changes were made. The images or other third party material in this article are included in the article's Creative Commons licence, unless indicated otherwise in a credit line to the material. If material is not included in the article's Creative Commons licence and your intended use is not permitted by statutory regulation or exceeds the permitted use, you will need to obtain permission directly from the copyright holder. To view a copy of this licence, visit http://creativecommons.org/licenses/by/4.0/.

\section{Appendix}

See Fig. 6.
Fig. 6 Kratky plots of never-dried (above) and dried and re-wetted samples (below). At the maximum, the fit is shown which has been used to identify the maximum (q position) when determining $\mathrm{d}_{\text {center }}$
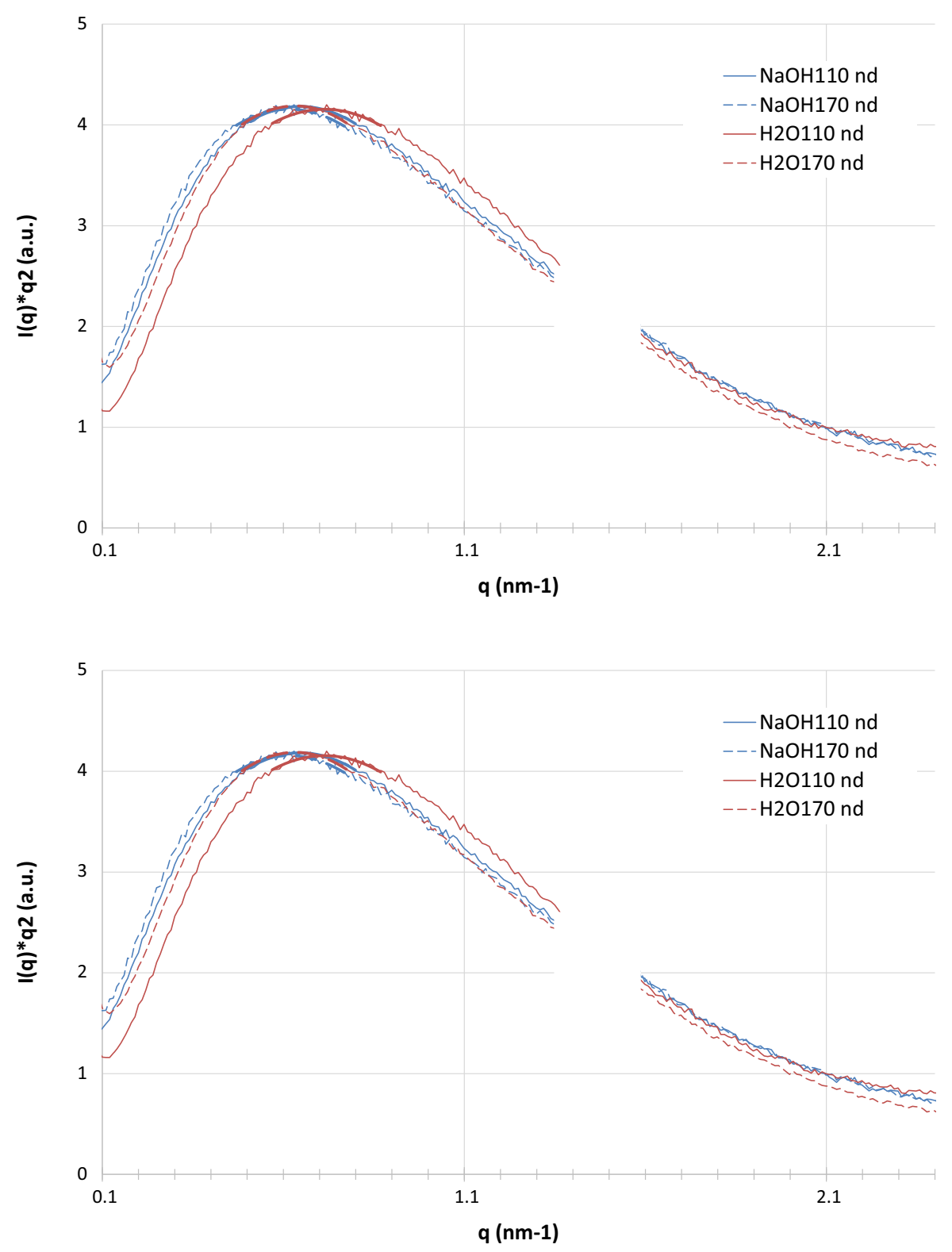


\section{References}

Adani F, Papa G, Schievano A, Cardinale G, D'Imorzano G, Tambone F (2011) Nanoscale structure of the cell wall protecting cellulose from enzyme attack. Environ Sci Technol 45:1107-1113. https://doi.org/10.1021/ es 1020263

Åkerholm M, Salmén L (2001) Interactions between wood polymers studied by dynamic FT-IR spectroscopy. Polymer 42:963-969. https://doi.org/10.1016/S00323861(00)00434-1

Aldaeus F, Larsson K, Stevanic SJ, Kubat M, Karlström K, Peciulyte A, Olsson L, Larsson PT (2015) The supramolecular structure of cellulose-rich wood pulps can be a determinative factor for enzymatic hydrolysability. Cellulose 22:3991-4002. https://doi.org/10.1007/s10570015-0766-0

Andreasson B, Forsström J, Wågberg L (2003) The porous structure of pulp fibres with different yields and its influence on paper strength. Cellulose 10:111-123. https://doi. org/10.1023/A:1024055406619

Axelsson S, Croon I, Enström B (1962) Dissolution of hemicelluloses during sulphate pulping. Svensk Papperstidn 65:693-697

Borrega M, Nieminen K, Sixta H (2011) Degradation kinetics of the main carbohydrates in birch wood during hot water extraction in a batch reactor at elevated temperatures. Bioresour Technol 102:10724-10732. https://doi.org/10. 1016/j.biortech.2011.09.027

Chen X, Lawoko M, van Heiningen A (2010) Kinetics and mechanism of autohydrolysis of hardwoods. Bioresour Technol 101:7812-7819. https://doi.org/10.1016/j. biortech.2010.05.006

Chunilall V, Bush T, Larsson PT, Iversen T, Kindness A (2010) A CP/MAS ${ }^{13} \mathrm{C}$-NMR study of cellulose fibril aggregation in eucalyptus dissolving pulps during drying and the correlation between aggregate dimensions and chemical reactivity. Holzforschung 64:693-698. https://doi.org/10. 1515/hf.2010.097

Cleland RL (1977) The persistence length of hyaluronic acid: an estimate from small-angle $\mathrm{x}$-ray scattering and intrinsic viscosity. Arch Biochem Biophys 180(1):57-68. https:// doi.org/10.1016/0003-9861(77)90008-X

Driemeier C, Pimenta M, Rocha G, Oliveira M (2011) Evolution of cellulose crystals during prehydrolysis and soda delignification of sugarcane lignocellulose. Cellulose 18:1509-1519. https://doi.org/10.1007/s10570-011-95921

Duchesne I, Daniel G (2000) Changes in surface ultrastructure of Norway spruce fibres during kraft pulping — visualisation by field emission-SEM. Nord Pulp Pap Res J 15:54-61. https://doi.org/10.3183/npprj-2000-15-01p054-061

Duchesne I, Hult E, Molin U, Daniel G, Iversen T, Lennholm H (2001) The influence of hemicellulose on fibril aggregation of kraft pulp fibres as revealed by FE-SEM and CP/MAS ${ }^{13}$ C-NMR. Cellulose 8:103-111. https://doi.org/10.1023/ A: 1016645809958

Fahlén J, Salmén L (2003) Cross-sectional structure of the secondary wall of wood fibres as affected by processing.
J Mater Sci 38:119-126. https://doi.org/10.1023/A: 1021174118468

Fahlén J, Salmén L (2005) Pore and matrix distribution in the fibre wall revealed by atomic force microscopy and image analysis. Biomacromol 6:433-438. https://doi.org/10. 1021/bm040068x

Garrote G, Dominguez H, Parajo JC (1999) Hydrothermal processing of lignocellulosic materials. Holz als Roh- und Werkstoff 57:191-202. https://doi.org/10.1007/ s001070050039

Hult E, Larsson PT, Iversen T (2001) Cellulose fibril aggregation-an inherent property of kraft pulps. Polymer 42:3309-3314. https://doi.org/10.1016/S00323861(00)00774-6

Inagaki T, Siesler H, Mitsui K, Tsuchikawa S (2010) Difference in the crystal structure of cellulose in wood after hydrothermal treatment and aging degradation: A NIR spectroscopy and XRD study. Biomacromol 9:23000-32305. https://doi.org/10.1016/S00323861(00)00774-6

Janson J (1974) Analytik der Polysaccharide in Holz und Zellstoff. Faserforschung und Textiltechnik 25:375-382

Jansson Z, Brännvall E (2011) Characterisation of dissolved spruce xylan in kraft cooking. Nord Pulp Pap Res J 26:380-385. https://doi.org/10.3183/npprj-2011-26-04p380-385

Jungnikl K, Paris O, Fratzl P, Burgert I (2008) The implication of chemical extraction treatments on the cell wall nanostructure of softwood. Cellulose 15:407-418. https://doi. org/10.1007/s10570-007-9181-5

Kafle K, Lee C, Shin H, Zoppe J, Johnson D, Kim S, Park S (2015) Effects of delignification on crystalline cellulose in lignocellulosic biomass characterized by vibrational sum frequency generation spectroscopy and x-ray diffraction. BioEnergy Res 8:1750-1758. https://doi.org/10.1007/ s12155-015-9627-9

Kuribayashi T, Ogawa Y, Rochas C, Matsumoto Y, Heux L, Nishiyama Y (2016) Hydrothermal transformation of wood cellulose crystals into pseudo-orthorhombic structure by cocrystallization. ACS Macro Lett 5(6):730-734. https:// doi.org/10.1021/acsmacrolett.6b00273

Langan P, Petridis L, O’Neill H, Pingali S, Foston M, Nishiyama Y, Schulz R, Lindner B, Hanson L, Harton S, Heller W, Urban V, Evans B, Gnanakaran S, Ragauskas A, Smith J, Davison B (2014) Common processes drive the thermomechanocal pretreatment of lignocellulosic biomass. Green Chem 16:63-68. https://doi.org/10.1039/ C3GC41962B

Larsson PT, Salmén L (2014) Influence of cellulose supramolecular structure on strength properties of chemical pulp. Holzforschung 68:861-866. https://doi.org/10. 1515/hf-2013-0226

Larsson PT, Wickholm K, Iversen T (1997) A CP/MAS ${ }^{13} \mathrm{C}$ NMR investigation of molecular ordering in celluloses. Carbohydr Res 302:19-25. https://doi.org/10.1016/S00086215(97)00130-4

Larsson PT, Svensson A, Wågberg L (2013) A new, robust method for measuring average fibre wall pore sizes in cellulose I rich plant fibre walls. Cellulose 20:623-631. https://doi.org/10.1007/s10570-012-9850-x 
Leppänen K, Andersson S, Torkkeli M, Knaapila M, Kotelnikova N, Serimaa R (2009) Structure of cellulose and microcrystalline cellulose from various wood species, cotton and flax studied by X-ray scattering. Cellulose 16:999-1015. https://doi.org/10.1007/s10570-009-9298-9

Malm E, Bulone V, Wickholm K, Larsson PT, Iversen T (2010) The surface structure of well-ordered native cellulose fibrils in contact with water. Carbohydr Res 345:97-100. https://doi.org/10.1016/j.carres.2009.10.020

Nilsson H, Galland S, Larsson PT, Gamstedt K (2012) Compression molded wood pulp biocomposites: a study of hemicellulose influence on cellulose supramolecular structure and material properties. Cellulose 19:751-760. https://doi.org/10.1007/s10570-012-9688-2

Nishiyama Y, Langan P, O’Neill H, Pingali S (2014) Structural coarsening of aspen wood by hydrothermal pretreatment monitored by small- and wide-angle scattering of X-rays and neutraons on oriented specimens. Cellulose 21:1015-1024. https://doi.org/10.1007/s10570-013-00692

Pääkkö M, Ankerfors M, Kosonen H, Nykänen A, Ahola S, Österberg M, Ruokolainen J, Laine J, Larsson PT, Ikkala O, Lindström T (2007) Enzymatic hydrolysis combined with mechanical shearing and high-pressure homogenization for nanoscale cellulose fibrils and strong gels. Biomacromol 8:1934-1941. https://doi.org/10.1021/ bm061215p

Paananen M, Liitiä T, Sixta H (2013) Further insights into carbohydrate degradation and dissolution behaviour during kraft cooking under elevated alkalinity without and in the presence of anthraquinone. Ind Eng Chem Res 52:12777-12784. https://doi.org/10.1021/ie4018012

Page D (1976) A note on the cell-wall structure of softwood tracheids. Wood Fiber Sci 7:246-248

Peciulyte A, Karlström K, Larsson PT, Olsson L (2015) Impact of supramolecular structure of cellulose on the efficiency of enzymatic hydrolysis. Biotechnol Biofuels 8:56. https:// doi.org/10.1186/s13068-015-0236-9

Penttilä PA, Kilpeläinen P, Tolonen LL, Suuronen JP, Sixta H, Willför S, Serimaa R (2013) Effects of pressurized hot water extraction on the nanoscale structure of birch sawdust. Cellulose 20:2335-2347. https://doi.org/10.1007/ s10570-013-0001-9

Pingali S, O'Neill H, Nishiyama Y, He L, Melnichenko Y, Urban V, Petridis L, Davison B, Langan P (2014)
Morphological changes in the cellulose and lignin components of biomass occur at different stages during steam pretreatment. Cellulose 21:2335-2347. https://doi.org/10. 1007/s10570-013-0162-6

Puls J, Poutanen K, Körner HU, Viikari L (1985) Biotechnical utilization of wood carbohydrates after steaming pretreatment. Appl Microbiol Biotechnol 22:416-423. https://doi. org/10.1007/BF00252783

Salmén L, Olsson AM (1998) Interaction between hemicelluloses, lignin and cellulose: structure-property relationships. J Pulp Pap Sci 24:99-103

Stone J, Scallan A (1967) The effect of component removal upon the porous structure of the cell wall of wood. II. Swelling in water and the fiber saturation point. Tappi 50:496-501

Virtanen T, Penttilä PA, Maloney T, Grönqvist S, Kamppuri T, Vehviläinen M, Serimaa R, Maunu SL (2015) Impact of mechanical and enzymatic pretreatments on softwood pulp fiber wall structure studied with NMR spectroscopy and X-ray scattering. Cellulose 22:1565-1576. https://doi.org/ 10.1007/s10570-015-0619-x

Wickholm K, Larsson PT, Iversen T (1998) Assignment of noncrystalline forms in cellulose I by CP/MAS ${ }^{13} \mathrm{C}$ NMR spectroscopy. Carbohyd Res 312:123-129. https://doi.org/ 10.1016/S0008-6215(98)00236-5

Wigell A, Brelid H, Theliander H (2007) Kinetic modeling of (galacto)glucomannan degradation during alkaline cooking of softwood. Nord Pulp Pap Res J 22:495-499. https:// doi.org/10.3183/npprj-2007-22-04-p495-499

Wollboldt P, Zuckerstätter G, Weber H, Larsson PT, Sixta H (2010) Accessibility, reactivity and supramolecular structure of E. globulus pulps with reduced xylan content. Wood Sci Technol 44:533-546. https://doi.org/10.1007/s00226010-0370-2

Yamamoto H, Horii F (1993) CPMAS carbon-13NMR analysis of the crystal transformation induced for Valonia cellulose by annealing at high temperatures. Macromolecules 26(6):1313-1317. https://doi.org/10.1021/ma00058a020

Publisher's Note Springer Nature remains neutral with regard to jurisdictional claims in published maps and institutional affiliations. 